http://jmscr.igmpublication.org/home/ ISSN (e)-2347-176x ISSN (p) 2455-0450

crossref DOI: https://dx.doi.org/10.18535/jmscr/v8i10.10

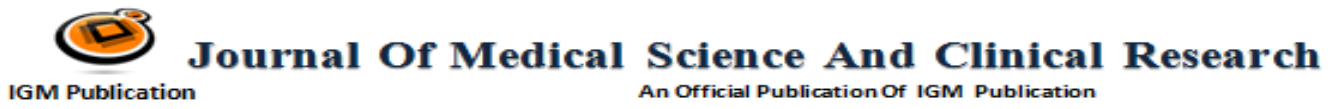

\title{
Case Report of COVID Positive Children Admitted in SLBSGMC Nerchowk Mandi
}

\author{
Authors \\ Dr Richa Sharma, Dr Vinod Kumar, Dr Vishal Jamwal, Dr Chandershekar, \\ Dr Pratima Thakur, Dr Pradeep Attri \\ Deptt of Pediatrics, Shri Lal Bhadur Shastri Govt Medical College, Nerchowk, Mandi, H.P \\ Corresponding Author \\ Dr Richa Sharma \\ Assistant Prof (Pediatrics)
}

\section{Introduction}

In December 2019, cluster cases of pneumonia were reported in Wuhan china and the source was a new type of coronavirus. Seven coronaviruses are known to cause disease in humans. Of these, HCoV-229E, HCoV-OC43, HCoV-NL63, and HCoV-HKU1 usually cause mild upper respiratory symptoms, and rarely cause serious disease. SARS-CoV and MERS-CoV infections can lead to severe lower respiratory tract symptoms with acute severe respiratory syndrome. SARS-CoV-2 belongs to the betacoronaviruses and can also infect the lower respiratory tract and cause pneumonia. On February 11, 2019. WHO declared the disease caused by SARS-CoV-2 as Coronavirus disease 2019 (COVID-19). Many studies have been reported in adults, but very less case reports are in pediatric age group. Fever, cough, and shortness of breath are common among adults however, these symptoms are less frequently reported symptoms amongst children. Myalgia, sore throat, headache, and diarrhea were also less reported symptoms. We are reporting eleven covid patients who tested positive by RT-
PCR and were symptomatic therefore admitted with us.

\section{Case Report}

There were total of eleven patients of the age group one day to fifteen years of age. Out of them five were males and six were females. All of them had a positive history of contact in form of parents or realtives. The most common presenting complaint was fever which was present in eight of them between the ranges of 99 to 102 degree Fahrenheit. Two of them had sore throat, one had cough and rhinorrhoea. Only one of the eleven patients, an eight years old male had high grade fever, cough, shortness of breath and $\mathrm{SaO} 2$ less than $88 \%$.He required oxygen support which was given for 48 hours and then tapered off. He was also administered with IV antibiotics in addition to paracetamol, vitD, $\mathrm{C}$ and zinc and azithromycin which were given to all of them. Investigations done were CBC, LFT, RFT, Electrolytes, CRP, ESR. Which were all within the normal range for all of the patients. However X-ray chest of one the patient who had respiratory distress and desaturation showed bilateral infiltrates in both 
right and left upper zones. Two of the patients reffered to us were patients admitted in pediatric ward but got exposed during the course of the illness. One of them was steroid resistant nephrotic syndrome and other was aplastic anamia under investigation. The course in hospital for all of them was uneventful without any serious complication and discharged in state of good health after follow up report for repeat RT PCR came out to be negative.

\section{Discussion}

Most of the children infected with COVID19 are asymptomatic or show mild clinical manifestations and recover within 1-2 weeks after disease onset ${ }^{(6)}$. Huang et al. reported that 40 (98\%) out of 41 adult COVID-19 patients had fever $^{(1)}$. In our report, $(80 \%)$ of the patients had fever during the course of the disease. SARSCoV-2 can also infect the lower respiratory tract and cause pneumonia as in one of them. The mortality rate associated with COVID-19 is generally lower than that of SARS and MERS ${ }^{(5,8-}$ 10). In the early phase of COVID-19 infection in our patients, the white blood cell count was normal. CRP levels were normal .X ray chest showed no abnormal changes except for one which had bilateral opacities.

\section{Conclusion}

In brief, COVID-19 in children is relatively occult or mild, and it is easy to miss the diagnosis in the early stages when present. Severe COVID-19 can also occur in children with underlying or coexisting disease.

\section{Bibliography}

1. Huang C, Wang Y, Li X, Ren L, Zhao J, $\mathrm{Hu} \mathrm{Y}$, et al. Clinical features of patients infected with 2019 novel coronavirus in Wuhan, China. Lancet.(2020) 395:497506.doi: 10.1016/S0140-6736(20)30183-5. PubMed Abstract | CrossRef Full Text | Google Scholar
2. Zhu N, Zhang D, Wang W, Li X, Yang B, Song $\mathbf{J}$, et al. A novel coronavirus from patients with pneumonia in China, 2019.N Engl J Med. (2020) 382:727-33.doi: 10.1056

3. Chen F, Liu ZS, Zhang FR, Xiong RH, Chen Y, Cheng XF, et al. First case of children infected with severe novel coronavirus pneumonia in China. Zhonghua ErKe ZaZhi. (2020) 58:17983.doi: $\quad 10.3760 / \mathrm{cma}$.j.issn.05781310.2020.03.003

4. Zeng LK, Tao XW, Yuan WX, Wang J, Liu $X$, Liu ZS. First case of neonate infected with novel coronavirus pneumonia in China. Zhonghua ErKe ZaZhi. (2020) 58:E009. doi: 10.3760/cma.j.issn.0578-1310.2020.00

5. Memish ZA, Al-Tawfiq JA, Assiri A, AlRabiah FA, Al Hajjar S, Albarrak A, et al. Middle East respiratory syndrome coronavirus disease in children. Pediatr Infect Dis J. (2014) 33:904-6. doi: 10.1097. 